\title{
Final Clinical Trial Close Out Monitoring Report
}

National Cancer Institute

\section{Source}

National Cancer Institute. Final Clinical Trial Close Out Monitoring Report. NCI Thesaurus.

Code C115581.

Records describing the findings of a site monitor at a site close-out visit prior to a trial's completion. 